Revista Eletrônica do Mestrado em Educação Ambiental

\title{
Lésbicas e Bissexuais em Narrativas Adolescentes: um olhar feminista sobre produções seriadas para TV e Internet
}

\author{
Daniela Auad ${ }^{1}$ \\ Universidade Federal de Juiz de Fora \\ https://orcid.org/0000-0002-9805-1708
}

Sabrina Fernandes Pereira Lopes ${ }^{2}$ Universidade Federal de Juiz de Fora https://orcid.org/0000-0002-5783-4976

Cláudia Regina Lahni ${ }^{3}$

Universidade Federal de Juiz de Fora https://orcid.org/0000-0001-6503-7179

Resumo: Ao focalizar personagens lésbicas e bissexuais em um conjunto de quatro obras audiovisuais ficcionais seriadas, que estrearam entre 2017 e 2019 , o presente artigo reflete sobrenarrativas para o público adolescente, tanto no modo de transmissão já consolidado em canais de televisão quanto com o crescente acesso pela internet. Séries e novelas com público alvo

\footnotetext{
${ }^{1}$ Doutora, Mestra e Pedagoga pela Faculdade de Educação da USP (Universidade de São Paulo), com pesquisa e ênfase de formação na área de concentração Sociologia da Educação. Pós- Doutora em Sociologia pela UNICAMP (Universidade Estadual de Campinas); Professora Permanente da linha Trabalho, Estado e Movimentos Sociais, no Programa de Pós- Graduação em Educação da Faculdade de Educação da Universidade Federal de Juiz de Fora (PPGE/FACED/UFJF). e-mail: auad.daniela@ gmail.com

${ }^{2}$ Graduada em Pedagogia pela Universidade Federal de Minas Gerais - UFMG e Mestra em Educação Tecnológica pelo Centro Federal de Educação Tecnológica de Minas Gerais - CEFET-MG. É doutoranda em Educação pela Universidade Federal de Juiz de Fora (UFJF). Participa do Grupo de Pesquisa Educação, Comunicação e Feminismos - Flores Raras, onde se concentra principalmente nas temáticas feminismos, lesbianidades, educação e cinema. e-mail: sabrinafpl@yahoo.com.br

${ }^{3}$ Pós-doutorada (2014) em Comunicação na Universidade do Estado do Rio de Janeiro (UERJ), doutorado (2005) e mestrado (1999) em Ciências da Comunicação pela Universidade de São Paulo (USP); especialização em Jornalismo (1996) pela Faculdade Cásper Líbero e graduação em Jornalismo (1990) pela Pontifícia Universidade Católica de Campinas. É Professora da Faculdade de Comunicação (Facom) da Universidade Federal de Juiz de Fora (UFJF). Professora permanente do PPGECH-UFSCar So (Programa de Pós-Graduação Estudos da Condição Humana Universidade Federal de São Carlos, Campus Sorocaba). Feminista, tem experiência na área de Comunicação, com ênfase em Jornalismo Comunitário e Ensino de Jornalismo, atuando principalmente nos seguintes temas: comunicação para a cidadania, comunicação comunitária, comunicação e relações de gênero, comunicação e lesbianidade, educomunicação, comunicação e educação, rádio comunitária, imprensa sindical, participação e cidadania. email:1ahni.cr@gmail.com
}

Rev. Eletrônica Mestr. Educ. Ambient. Rio Grande, Dossiê temático "Imagens: resistências e criações cotidianas", p.230-252, jun. 2020. E-ISSN 1517-1256 
adolescente ou familiar, com protagonismo adolescente e que apresentam personagens lésbicas e/ou bissexuais de destaque foram selecionadas e colocadas a dialogar com autoras que abordamDireito à Comunicação no contexto das tecnologias digitais, Feminismos nos campos da Comunicação e Educação e Feminismo Lésbico. Autodescoberta, autoconhecimento e relações familiares foram centrais nas produções pesquisadas.Temáticas a partir das quais são debatidas as relações entre cidadania comunicativa e mulheres lésbicas e bissexuais.

Palavras-chave: Feminismos. Lesbianidades. Cultura Visual.

\title{
Lesbianas y bisexualesen narrativas adolescentes: una mirada feminista a
}

\section{lasproduccionesenserie para TV e Internet}

Resumen:Al centrarse en personajes lésbicos y bisexuales en un conjunto de cuatro obras audiovisuales fictícias en serie, que se estrenó entre 2017 y 2019, este artículo refleja sobre narraciones para el público adolescente, tanto en el modo de transmisión ya consolidado en los canales de televisión como con el creciente acceso de Internet. Se seleccionaron series y telenovelas con un público objetivo adolescente o familiar, con protagonismo adolescente, y con personajes prominentes de lesbianas y / o bisexuales y se dialogaron con autoras que abordan el Derecho a la Comunicación en el contexto de las tecnologías digitales, los feminismos en los campos de la Comunicación y Educación y Feminismo Lesbiano. El autodescubrimiento, el autoconocimiento y las relaciones familiares fueron fundamentales para las producciones investigadas, temáticas desde las cuales se debaten las relaciones entre la ciudadanía comunicativa y las mujeres lesbianas y bisexuales.

Palabras clave: Feminismos. Lesbianas. Cultura Visual.

\section{Lesbians and Bisexuals in Teen Narratives: a feminist look at serial productions for}

\section{TV and Internet}

\begin{abstract}
By focusing on lesbian and bisexual characters in a set of four serial fictional audiovisual works, which premiered between 2017 and 2019, this article reflects on narratives for teen audiences, both in the mode of transmission already consolidated on television channels and with the increasing access by Internet. Series and soap operas with an adolescent or family target audience, with adolescent protagonism, and featuring prominent lesbian and / or bisexual characters were selected and placed in dialogue with authors who address the Right to Communication in the context of digital technologies, Feminisms in the fields of Communication and Education and Lesbian Feminism. Self-discovery, self-knowledge and family relationships were central to the researched productions, thematic from which the relations between communicative citizenship and lesbian and bisexual women are debated.
\end{abstract}

Keywords: Feminisms.Lesbians. Visual Culture.

\section{A introdução de um olhar feminista e lésbicosobre produções seriadas}

Diante dos constantes e intensos ataques à democracia e aos direitos de variadas populações historicamente subalternizadas, colocamo-nos a refletir, de modo científico e poético, sobre produções audiovisuais que correspondem às imagens representativas do nosso cotidiano, da nossa cultura e da ambiência dos grupos e dos movimentos sociais dos quais fazemos parte, nos quais acolhemos, somos acolhidas e dos quais participamos da imprescindível construção. Nessa conjuntura, vale notar que a importância e centralidade

Rev. Eletrônica Mestr. Educ. Ambient. Rio Grande, Dossiê temático "Imagens: resistências e criações cotidianas", p.230-252, jun. 2020. E-ISSN 1517-1256 
da Comunicação na sociedade contemporânea já foi tematizada por autoras diversas.E, ao entendermos tal importância, interessa-nos pensar, conceituar e militar pela democratização da comunicação, tendo em vista avasta relação que a comunicação estabelece como agência socializadorae a sua contribuição para o exercício da cidadania de todas as pessoas.Nesse sentido, questionamos se é possível pensar em direitos, a partir de produtos da chamada indústria cultural. Avaliamos que sim, como aponta Carlos Eduardo Lins da Silva ${ }^{4}$ (1986) que, ao analisar comunicação popular e alternativa, revela as inserções em brechas - estas como um espaço diferente e alternativo ao que se percebe como massivo. Trata-se de termos possibilidades na chamada indústria criativa e quando do uso das novas tecnologias, para expandir o caráter socializador da comunicação, no que se refere especialmente aos direitos e à representatividade de variados grupos populacionais geralmente invisibilizados.

Assegurar a aparição representativa e o reconhecimento longe de modelos discriminatórios remonta aos processos que garantem a comunicação como direito, ao que lembramos o conceito de Cidadania Comunicativa, da teórica argentina Maria Cristina Mata. A autorapondera sobre a necessidade do exercício do direito à comunicação para a cidadania efetiva na sociedade atual. Esalienta a importância da comunicação, em especial, na América Latina, para aquelas/es que são silenciados/as por confrontarem o sistema hegemônico, pensarem de maneira distinta ou adotarem modos de vida que não são reconhecidos como legítimos pelo sistema dominante (MATA, 2010).

Diante disso, e como também mencionam Cláudia Lahni e Daniela Auad (2019),lembramos que as mulheres e em especial as mulheres LBT (Lésbicas, Bissexuais e Transexuais) formam um grupo minoritário - que soma metade da população - muitas vezes silenciado nas produções audiovisuais, sub-representadoquando raramente lembrado,ou, na maioria das vezes, fora da mídia como um todo, se considerarmos a multiplicidade de sujeitos apagados.

Na mencionada publicação, as autoras apresentam uma breve reflexão sobre o filme Grandma de 2015, com direção, roteiro e produção de Paul Weitz. O roadmovie feminista conta a história de uma mulher lésbica, feminista, viúva, avó de uma netae mãe de uma filha.Para a versão brasileira, o título se tornou Aprendendo com a vovó.

\footnotetext{
${ }^{4}$ Ao aparecer pela primeira vez como referência, será citado o primeiro nome da autora ou do autor. Essa medida busca evitar o masculino genérico assumido durante a leitura do texto, mais comum quando são utilizados apenas os sobrenomes ao mencionar as referências bibliográficas.
}

Rev. Eletrônica Mestr. Educ. Ambient. Rio Grande, Dossiê temático "Imagens: resistências e criações cotidianas", p.230-252, jun. 2020. E-ISSN 1517-1256 
Figura 1: A avó interpretada por Lily Tomlin, com a neta, interpretada por Julia

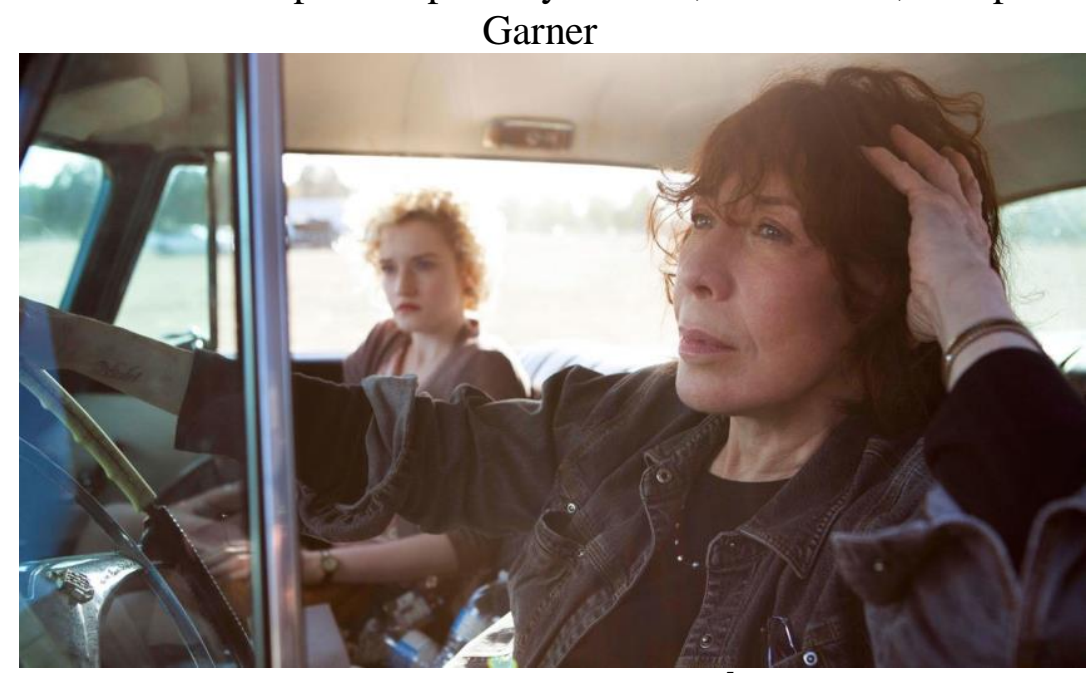

Fonte:Cine Suffragette

Consideramos que um filme como esse é muito importante "porque nos vemos retratadas, representadas, apresentadas" (LAHNI E AUAD, 2019, p. 127). Tais processos e sentimentos têm significativa importância para a vida das mulheres lésbicas e bissexuais, assim como para todas as pessoas. Nas telas figuram possíveis modos de ser, de sentir, de se deslocar e sair dos lugares inicialmente pensados para mulheres, homens, de variadas idades e gerações. Nesse sentido, para além da importância do cinema, como arte e comunicação, temos refletido sobre as presenças e ausências de mulheres LBT na televisão e outros produtos audiovisuais, como uma maneira de ampliar os itinerários das subjetividades, os deslocamentos e as invenções de si, como aponta Nádia Nogueira em seu livro sobre Elisabeth Bishop e Lota de Macedo Soares (2008). Na obra, a autora analisa a necessidade de renunciar a certas formas de silenciamento históricas; valoriza como houve(entre as mulheres lésbicas)a construção de uma performance cultural diferenciada, não mais referendada nos atributos das identidades sexuadas; e, ainda, explora como a experiência nessa relação sexual e afetiva possibilita pensar a constituição

\footnotetext{
${ }^{5}$ A cada imagem ilustrativa das produções citadas no presente texto, será divulgado os links de blogs ou sites, dos quais as imagens exibidas foram retiradas. Para coletar as referidas imagens, foram selecionados blogs e sites feministas, de modo que, em um só tempo, será revelada a fonte da imagem e será divulgado, no interior do presente texto, um espaço virtual de debate e de encontro de movimentos sociais e variados grupos e indivíduos, como jovens, feministas e populações negra e lgbt. Com essa sistemática de escrita e de divulgação este texto explicita que o debate aqui tecido não se inicia e nem se esgota aqui, mas nestas páginas se busca agregar, contribuir e dialogar. No caso da imagem referente ao filme Grandma, desta nota, o blog do qual se retirou a foto é o seguinte: https://medium.com/cinesuffragette/aprendendo-com-a-vov\%C3\%B3-2015-b43b4ff47507
}

Rev. Eletrônica Mestr. Educ. Ambient. Rio Grande, Dossiê temático "Imagens: resistências e criações cotidianas", p.230-252, jun. 2020. E-ISSN 1517-1256 
de um estilo de vida distinto do tradicional, com práticas de subjetivação nas quais as mulheres podem desenvolver formas de relação consigo mesmo e, assim, participar de suas construções como indivíduos e colaborando na tessitura de novas relações cotidianas.

Figura 2: À esquerda, Elisabeth Bishop; à direita, Lota de Macedo Soares

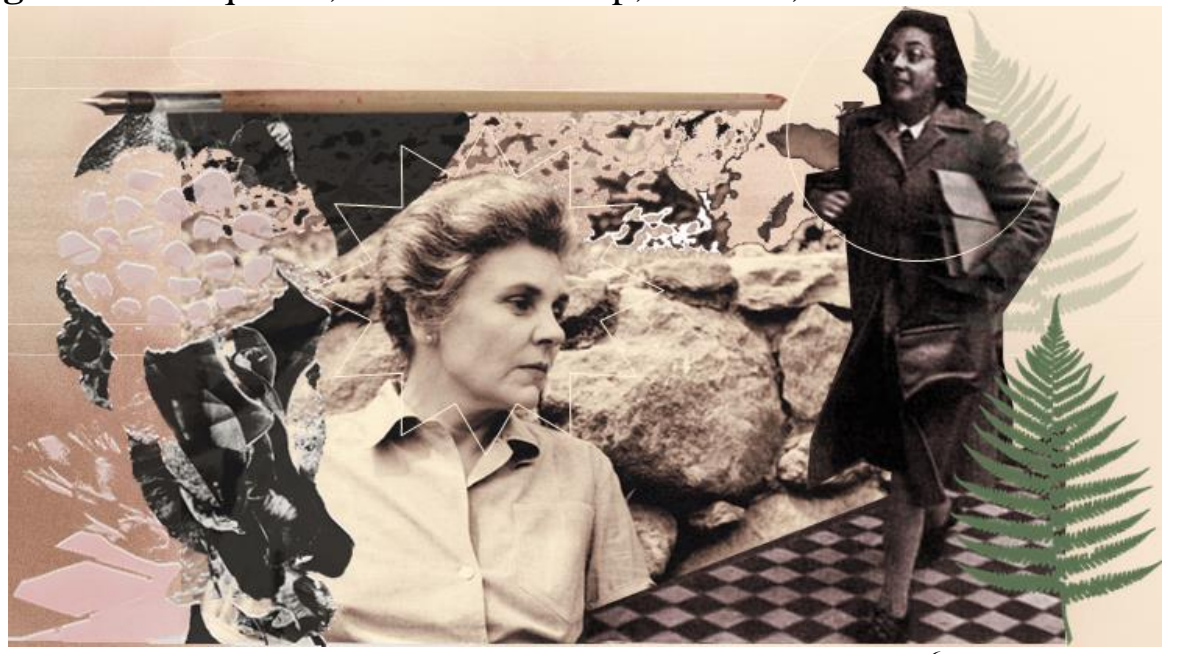

Fonte: Foto colagem do site Valkirias ${ }^{6}$.

Bem, se tudo isso pode-se dizer de uma história de amor e de invenções de si que se passou sob o céu de Samambaia (NOGUEIRA, 2005, p. 228) - cidade na serra fluminense, a caminho de Minas Gerais, onde Lota e Bishop edificaram sua casa, sua relação, seus afetos e a si mesmas -, o que dizer de histórias de mulheres, entre mulheres, para mulheres e sobre mulheres amplificadas pela Mídia, seja como agência socializadora, seja como quando percebida como Quarto Poder, ao lado do Executivo, Legislativo e Judiciário?

Na inspiradora obra Dos meios às mediações, o espanhol JésusMartin-Barbero discorre sobre a importância do rádio e (na sequência) da televisão para a América Latina, a qual é marcada pela oralidade, em sua cultura. Aponta a fragmentação do romance, apresentado em dispositivos de fragmentação da leitura: "boa parte do sucesso 'massivo' do folhetim residia aí: numa fragmentação do texto escrito que incorporava os cortes 'produzidos' por uma leitura não especializada” (MARTIN-BARBERO, 1997, p.193). Na América Latina, em razão da centralidade da cultura oral, a televisão passa a ser assumida como o rádio com imagens e, nesse sentido, o autor aponta a importância do melodrama, presente em diferentes formatos como a novela e outros.

Com tais bases teóricas, Ryan Brandão Assis, Daniela Auad e Cláudia Lahni (2013) refletem, em artigo sobre a série Glee, a maneira como as tão conhecidas narrativas fracionadas -as séries -são capazes de despertar, ao mesmo tempo, audiência e interesse

${ }^{6} \mathrm{http} / /$ valkirias.com.br/entre-versos-e-samambaia-elizabeth-bishop-lota-soares/

Rev. Eletrônica Mestr. Educ. Ambient. Rio Grande, Dossiê temático "Imagens: resistências e criações cotidianas", p.230-252, jun. 2020. E-ISSN 1517-1256 
teórico. Ao analisar o seriado dirigido a jovens e transmitido, primeiramente, por TV por assinatura edepois aberta,o objetivo das autoras e autor foi pensar sobre a presença de mulheres e homossexuais na série. Esta seria uma produção audiovisual eficaz no tocante ao compartilhamento de referências comuns sobre representações das realidades sociais, possibilitando, dessa forma, a inclusão de grupos considerados minoritários (ASSIS; AUAD; LAHNI, 2013).

Novas formas de acessar produções audiovisuais têm surgido a partir da criação da internet. Se anteriormente as exibições eram reservadas às salas de cinema ou às transmissões televisivas, atualmente é possível assisti-las utilizando diversos dispositivos. Com isso, surge uma gama maior de conteúdos entre os quais escolher. Um marco dessa mudança foi o lançamento do YouTube em 2005. O site - atualmente,com mais de 1,9 bilhão de usuários, versões locais em 91 países e em 80 idiomas (YOUTUBE, s/d) - foi criado inicialmente para prover armazenamento de vídeo mas rapidamente se tornou uma plataforma também para distribuição, uma vez que, além de armazenar, permite que as pessoas acessem o conteúdo postado pelos demais, como lembra o estudo sobre audiovisual na cibercultura, de Wagner Miranda (2017, p.13).Crescem também os sites que disponibilizam, sob demanda e através de assinaturas pagas, séries e filmes feitos e distribuídos profissionalmente por grandes empresas. Nessa área há destaque para a Netflix que começou a operar no Brasil em 2011, mas há outros serviços de streaming sob assinatura, empresas que produzem e adquirem direitos de reprodução de programas especificamente para a internet e ainda os canais de televisão já consolidados também começaram distribuir seus conteúdos através de sites próprios. São exemplares desses serviços o Prime Vídeo, a HBO, a HBO GOe o Globo Play (Augustin BERTRAN, 2019).

Para Guillermo Orozco Gómez (2014, p.121), as alterações na interação entre audiências e telas não se definem apenas a partir das novas tecnologias. Há uma mudança nessa participação a depender de um esforço intencional de todas as pessoas e grupos, inseridos ou não nos Movimentos Sociais, envolvidos nos processos comunicativos. Dessa forma, no presente artigo procura-se identificar e relacionar temas perceptíveis em determinadas obras audiovisuais disponíveis on-line, com elementos observáveis da interação do público em torno delas.Sendo esses elementos e temas também bandeiras presentes nas lutas por direitos de variadas populações e, especialmente no caso deste estudo, dos movimentos feministas e de mulheres lésbicas e bissexuais.

Wagner Miranda (2017), ao analisar especificamente o caso da Netflix, aponta que a empresa adota um modelo de cauda longa, ou seja, além de investir na produção e Rev. Eletrônica Mestr. Educ. Ambient. Rio Grande, Dossiê temático "Imagens: resistências e criações cotidianas", p.230-252, jun. 2020. E-ISSN 1517-1256 
aquisição de obras com potencial de agradar a um grande público, também investe em conteúdos considerados de nicho, isto é, voltados para públicos específicos e menos numerosos. Essa seria uma nova característica que diferencia o modo de atuação nesse contexto específico, uma vez que não há mais a limitação imposta pelo horário de programação ou número de salas a que a televisão e o cinema estariam submetidos. Entre os públicos que vêm sendo abrangidos nessas novas condições, estão alguns historicamente invisibilizados no audiovisual, como LGBTs (Lésbicas, Gays, Bissexuais, Travestis, Transexuais e Transgêneros).

Cláudia Lahni e Daniela Auad (2018), ao tratar da presença de mulheres lésbicas, bissexuais e transexuais em séries, afirmam:

\begin{abstract}
A partir dos escritos ora desenvolvidos, essas mulheres LBT podem ser reconhecidas como a pièce de résistance da democracia, uma vez que as especificidades das discriminações com as quais convivem e as exclusões às quais são submetidas podem ser utilizadas como marcadores da cidadania que ainda não alcançamos (p.106).
\end{abstract}

Levando em conta esse relevante contexto, neste artigo são focalizadas narrativas seriadas para público adolescente que apresentam personagens lésbicas e/ou bissexuais. Foram selecionadas séries e novelas com público alvo adolescente ou familiar e neste último caso verificou-se a existência de protagonismo adolescente e presença de personagens lésbicas e/ou bissexuais de destaque.

As obras selecionadas foram EverythingSucks!(criação de Ben York Jones e Michael Mohan, 2018), One Day at a Time (criação de Gloria Calderon Kellett e Mike Royce, 2017-), Malhação: Viva a Diferença (direção de Paulo Silvestrini e Roteiro de Cao Hamburguer, 2017-2018) e Anne Withan E (criação de Moira Walley-Beckett, 2017-). A escolha se deu levando em conta o público para o qual as produções são voltadas. Foi critério também a existência de pelo menos um episódio cujo tema esteja diretamente relacionado às lesbianidades. A divisão aqui adotada serve aos propósitos de triagem das séries e novelas entre as demais que surgiram durante o levantamento feito para a escrita deste artigo, compreendido entre 2016 e 2019. Assim, algumas produções adolescentes de grande popularidade e que apresentam em algum momento relacionamentos amorosos entre mulheres ou personagens lésbicas e bissexuais, como StrangerThings (criação de Matt Duffer e Ross Duffer, 2016-) e Euphoria (criação de Sam Levinson, 2019-) não foram incluídas, uma vez que não se encaixam em dois critérios utilizados.

Seguindo um procedimento que se inspira no trabalho de Rebecca Beirne (2012), 
em sua tentativa de identificar convergências entre filmes com narrativas lésbicas adolescentes, não se buscou identificar a forma ou o gênero, nem outros aspectos narrativos. Foram buscados os assuntos abordados e como eles podem ser portas para a discussão das lesbianidades e dos feminismos. Tendo em vista que, conforme afirma bellhooks (2011):

Engajar-se na discussão crítica desses critérios [político e ideológico] não significa automaticamente desmerecer a produção. Negar a validade de uma crítica estética que inclua o ideológico e o político é mascarar o fato de que todo trabalho estético incorpora o político e o ideológico como parte de sua estrutura fundamental (p.198).

A autodescoberta, o autoconhecimento e as relações familiares são temáticas centrais nas produções analisadas e se ligam à lesbianidade de alguma forma em todas, de modo a forjar discussões sobre a descoberta da sexualidade, sobre a reação familiar frente à "saída do armário" e (ainda) sobre a importância da existência de personagens LGBTs adultos, em narrativas infanto-juvenis. Todas essas temáticas se relacionam ao enfretamento e combate à LGBTfobia, o que também é um ponto analisado nas produções que doravante serão focalizadas no recorte do presente texto.

\section{Os (não) lugares das lésbicas e das bissexuais em narrativas adolescentes seriadas}

Ao focalizar personagens lésbicas e bissexuais em um conjunto de quatro obras audiovisuais ficcionais seriadas, que estrearam entre 2017 e 2019, o presente artigo reflete sobre narrativas para o público adolescente, tanto no modo de transmissão já consolidado em canais de televisão quanto com o crescente acesso pela internet. Assim, foram selecionadas para reflexão séries com público alvo adolescente ou familiar, com especial protagonismo adolescente e cujas personagens lésbicas e/ou bissexuais possibilitam dialogar a partir de concepções do Direito à Comunicação no contexto das tecnologias digitais, dos Feminismos nos campos da Comunicação e da Educação e do Feminismo Lésbico. Estas abordagens foram os óculos que usamos para conhecer e reconhecer os lugares - ou a ausência de lugar - das mulheres jovens lésbicas e bissexuais.

Em EverythingSucks!,série disponibilizada pela Netflix em 2018, o protagonismo é dividido entre dois personagens: Luke, um garoto negro que acaba de ingressar no ensino médio e Kate uma garota branca veterana. 
Figura 3: Parte do elenco de EverythingSucks!, sendo à frente, da direita para a esquerda, Kate e Luke

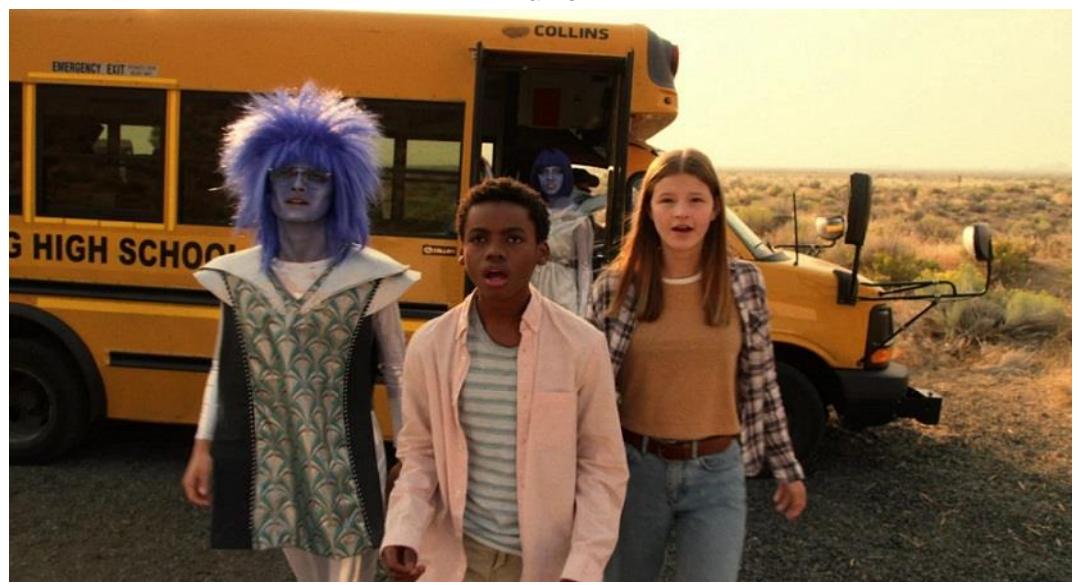

Fonte: Delirium Nerd .

Nesta série é importante salientar a questão racial, uma vez que desde o lançamento do trailer da série (KINOCHECK INTERNACIONAL, 2018), ela recebeu comentários racistas condenando a suposta representação de um casal inter-racial. EverythingSucks! procura instrumentalizar a nostalgia, estratégia que é identificada como recorrente nas produções da empresa, de modo a seguir uma linha semelhante àquela observada em StrangerThings (2016-), conforme apontam Mayka Castellano e Melina Meimaridis (2017), ao refletirem sobre produção televisiva e instrumentalização da nostalgia, especialmente no caso das séries da Netflix.

Figura : Eleven e Max, de Strangers Things

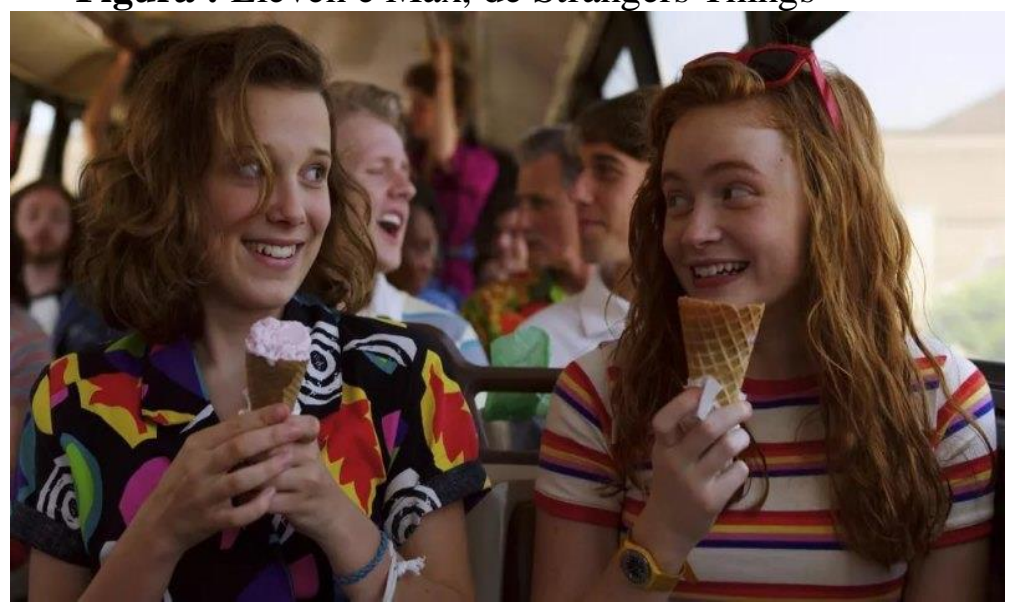

Fonte: Minas Nerds ${ }^{8}$.

\footnotetext{
${ }^{7}$ https://deliriumnerd.com/2018/04/11/everything-sucks-anos-90/ ${ }^{8} \mathrm{http}: / /$ minasnerds.com.br/2019/07/10/stranger-things-e-das-mulheres/

Rev. Eletrônica Mestr. Educ. Ambient. Rio Grande, Dossiê temático "Imagens: resistências e criações cotidianas", p.230-252, jun. 2020. E-ISSN 1517-1256
} 
Enquanto a primeira série reúne diversas referências a filmes de aventura e ficção científica dos anos 1980, na segunda é possível identificar alusões à cultura da década seguinte (1990), com foco principal em produções sobre o contexto escolar e romântico. No trailer de EverythingSucks! aparecem planos em que Kate e outra personagem mulher interagem.Mas, ainda no trailer, a maior parte das cenas é preenchida com interações entre Kate e Luke, o que, de fato, acaba por sugerir algum envolvimento romântico entre os dois. Porém e apesar disso, um dos principais conflitos da narrativa é que, ainda que Luke se interesse pela jovem colega de escola, Kate é lésbica. A série inicia mostrando uma história que parece ser de romance nos moldes "garoto encontra garota". O envolvimento entre eles se dá de forma bastante similar a tais comédias românticas, com o garoto traçando estratégias para conquistar a garota. Contudo, a orientação sexual da protagonista aparece no texto da narrativa já nos primeiros episódios. Kate e Luke se tornam amigos e, como também ocorre muitas vezes fora das séries, eles acabam engatando um namoro de fachada, para que as demais personagens não percebam que ela é lésbica. Tal situação acaba se mostrando insustentável, após o garoto insistir em externar constantemente seus sentimentos românticos por ela.

A descoberta da lesbianidade aparece como tema recorrente, o que não se mostra no trailer. Além do receio de que outros percebam, a história acompanha Kate se questionando sobre si mesma, em sua trajetória de autoconhecimento e autodescoberta.

No sexto episódio da única temporada, Luke compra um ingresso para um show da cantora Tori Amos, de quem ele sabe que Kate gosta, na tentativa de impressioná-la apesar da garota já ter revelado sua orientação sexual para ele a essa altura da série. No show, durante os versos "Eu disse que às vezes, ouço a minha voz/ E ela esteve aqui/ silenciada todos esses anos" (AMOS, 1992, tradução nossa), Kate observa um casal de mulheres na platéia e sorri. Depois do fim do espetáculo, Kate e Luke conversam sobre quão boa foi a aventura e Luke afirma que foi o melhor "encontro" de todos, o que gera uma discussão com Kate, pois ela responde que não foi um encontro. A jovem lésbica ainda reafirma que eles não são e nunca serão um casal de verdade. Kate revela como se sentiu acolhida naquele meio, fala sobre como sempre foi a garota estranha na escola e que agora percebia que poderia haver um futuro em que ela pudesse ser ela mesma. Luke questiona o porquêde ela estar fazendo isso com ele, ao que Kate responde: "A questão não é você!”. Os dois terminam o episódio brigados.

Evidenciam-se, assim, dois aspectos de interesse no episódio citado. Em primeiro lugar, a tentativa, sublinhada no roteiro da série, de quebrar com a linha narrativa Rev. Eletrônica Mestr. Educ. Ambient. Rio Grande, Dossiê temático "Imagens: resistências e criações cotidianas", p.230-252, jun. 2020. E-ISSN 1517-1256 
recorrente em comédias românticas. Tal narrativa repete, em variadas produções, que insistir por tempo suficiente é garantia para que um homem conquiste uma mulher, mesmo que ela seja lésbica. Isso ocorre, por exemplo, no filme Procura-se Amy (direção de Kevin Smith, 1997). Esse filme parte exatamente dessa premissa e integra a famosa coleção intitulada The CriterionCollection,dedicada a filmes importantes clássicos e contemporâneos. Em segundo lugar, em EverythingSucks! há de se destacar, no citado, o quanto Kate percebe e anseia realmente viver sua sexualidade livremente, durante um show onde vê um casal de mulheres adultas. Destaca-se que mostrar a possibilidade de um futuro em que sua identidade seja motivo de orgulho e felicidade é de grande importância em programas juvenis, tanto para jovens LGBTs quanto para heterossexuais e cisgêneros. Cenas como essas importam para que estes, heteros e cis, possam aprender a conviver, respeitar e admirar também essas relações, e para que jovens LGBTs possam existir sem se sentirem fora do lugar, seja diante dos seus corpos, seja na sociedade, ambos em contínua construção.

É sintomático que, das séries aqui selecionadas, EverythingSucks! é a única a ter atualmente o status "cancelada". Ela é também a única em que a lesbianidade é o fio condutor do principal conflito da trama.

One Day at a time é uma série familiar de comédia. É baseada em outra série de mesmo nome que foi ao ar entre 1975 e 1984 nos Estados Unidos. No remake da Netflix, a família é composta pela mãe Penélope, seus filhos Alex e Elena e a mãe de Penélope, Lydia que é uma imigrante cubana.

Figura 5: Imagem da família de Elena

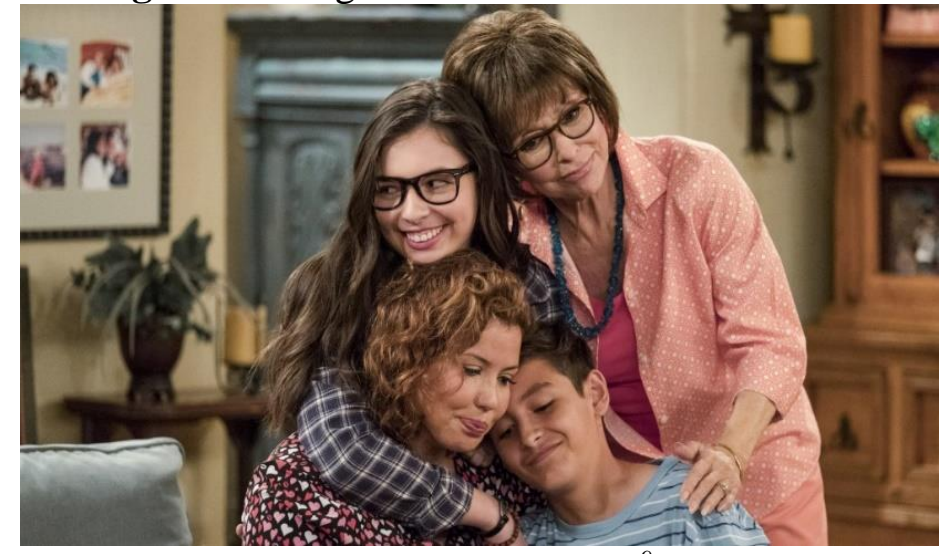

Fonte: Sommelier de Opinião ${ }^{9}$

\footnotetext{
${ }^{9}$ https://medium.com/@ sommelierdeopiniao/one-day-at-a-time-depress\%C3\%A3o-temas-lgbtq-feminismo-e-anecessidade-da-esperan\%C3\%A7a-2f46c3a2ac40
}

Rev. Eletrônica Mestr. Educ. Ambient. Rio Grande, Dossiê temático "Imagens: resistências e criações cotidianas", p.230-252, jun. 2020. E-ISSN 1517-1256 
A série já iniciou sua divulgação com um trailerem que sugere tratar de questões como a xenofobia sofrida por latinos nos EUA e o protagonismo de mulheres de diferentes gerações. Além dessas questões, estão presentes discussões em torno da depressão, dificuldades financeiras e tentativa de alcançar sucesso profissional sendo mãe e sustentando a família. A filha, Elena, é abertamente feminista, muito embora seu ativismo - sugerido como "excessivo" - seja alvo de piadas esporádicas ao longo dos episódios. Na primeira temporada da série há dois episódios que tratam mais especificamente da "saída do armário" da personagem. Em "Papo sobre aquilo", Penélope encontra vídeos pornográficos no computador e acaba descobrindo que quem assistia aos vídeos era Elena. Ao tentar conversar com ela sobre sexo seguro, supondo que a garota esteja sexualmente envolvida com um colega de escola, Penélope acolhe a revelação da jovem, que afirma não se ver no futuro namorando homens, mas se relacionando com mulheres. Tanto esse episódio quanto o seguinte possibilitam uma reflexão sobre a heterossexualidade compulsória, como explora em sua obra AdrienneRich (2019). No início, Elena se envolve realmente com um garoto, tendo em vista que este é o modelo apresentado como disponível e correto a todas as mulheres. A partir dessa experiência e de como ela não a satisfaz, a garota passa a contemplar a lesbianidade como uma possibilidade, reafirmando nos episódios, ao longo do desenvolvimento do enredo, as questões da autodescoberta pertinentes à existência lésbica. Por conseguinte, a mãe de Elena também lida com a própria dificuldade e frustração de perceber que os planos que havia feito para ela, calcados na presunção da heterossexualidade da filha, não serão realizados da forma que pensou.

O episódio seguinte começa com Penélope indo até a casa do amigo e vizinho Scheider e contando que não está se sentido tão bem como gostaria com relação à notícia de que Elena é lésbica. A mãe percebe, nessa conversa, que a forma como irá reagir pode afetar a vida futura da filha. Enquanto lida também com o medo de que a própria mãe, avó da jovem, saiba e reaja negativamente, uma vez que a matriarca da família é uma católica fervorosa. Apesar desse temor, a avó acaba por se resolver muito rapidamente com o argumento de que Deus nos criou sua imagem e semelhança e que ele não comete erros, portanto ela não teria o que julgar. A rapidez com que Lydia aceita a situação é introduzida na narrativa como uma contraposição às dificuldades da filhaPenélope, mãe de Elena e mais jovem uma geração. Tais dificuldades só se solucionam ao final do episódio, quando ela compartilha novamente uma conversa afetuosa com a filha.

Nas duas temporadas seguintes, temos evoluções diferentes da personagem Elena, Rev. Eletrônica Mestr. Educ. Ambient. Rio Grande, Dossiê temático "Imagens: resistências e criações cotidianas", p.230-252, jun. 2020. E-ISSN 1517-1256 
em situações que permanecem envolvendo a família e sua lesbianidade, como o primeiro namoro e episódios de lesbofobia. Após o fim da terceira temporada, a Netflix anunciou que a série seria cancelada, o que gerou um grande movimento de fãs na internet. Ao observar o Twitter é possível fazer uma aproximação do que descreve Guillermo Orozco Gómez (2014, p. 119), ao analisar educomunicação, recepção midiática, cidadania e aprendizado de participação. É perceptível como a referida rede social foi inundada pela hashtag \#SaveODAAT, em uma campanha para que a série fosse renovada. Frente às numerosas manifestações, a Netflix manteve a decisão de descontinuar a série. Outros canais de televisão manifestaram o interesse de adquirir os direitos para dar continuidade, porém, foram também negadas pela Netflix. Devido às cláusulas contratuais que impediam a série de ser distribuída por outros canais de streaming, a série foi salva por um canal menor de televisão, o PopTV, pertencente ao grupo CBS que dará continuidade à série em uma quarta temporada. Resta evidente nesta situação a maneira como o acesso à internet, a exibição e debate da série por essa mídia tornam a disputa pelo enredo e até destino da produção algo de interativo com o público e, portanto, com setores de movimentos sociais que lutam pelo reconhecimento e representatividade também nas telas, sejam de TV ou de computadores, tablets e celulares.

Dessa forma, vemos uma mudança na era do streaming, com uma série sendo "salva" por um movimento de fãs, cuja solução de exibição desemboca novamente na mídia tradicional, a televisão, que permanece tendo forte influência na era digital. Wagner Miranda (2017), ao refletir sobre produção e recepção do audiovisual na cibercultura, encontra novos hábitos na contemporaneidade e salienta o movimento contrário ao cancelamento advindo da mesma empresa. Trata-se da tendência da Netflix "resgatar" séries canceladas por canais de televisão, se valendo de sua capacidade de lucrar com conteúdos desenvolvidos para os diferentes nichos. Contudo, no caso da série One Day at a time vemos a situação se inverter. A possibilidade de existência da série foi criada através da lógica que permite o desenvolvimento e escuta de determinado nichoe, após a produção se mostrar popular, assegurou-se seu lugar na televisão, a partir de clamores de continuidade e sucesso de audiência.

Êxito semelhante foi conhecido no Brasil com a Malhação: Viva a Diferença (Globo, 2017-2018). Na produção nacional, o tipo de obra de narrativa seriada mais popular tem sido ao longo dos anos a telenovela. Entre as voltadas para o público adolescente, a primeira e bastante popular é Malhação, como aponta Lídia Coutinho (2008), estudiosa desta específica telenovela e seus modos de endereçamento. Produzida 
desde 1995, entre 2017 e 2018, Malhação, ao ser exibida em sua $25^{\text {a }}$ temporada, foi intitulada "Viva a Diferença". Tal remarque e destaque à diferença, em edição escrita por Cao Hamburguer, buscavam "confrontar e celebrar diferenças" (Lucas MEDEIROS, 2017).

O protagonismo foi dividido entre cinco personagens que ficaram amigas após uma delas ter um bebê num vagão de metrô. São elas, Keyla que dá a luz no primeiro dos 214 episódios da temporada; Benê, uma garota no espectro autista; Tina, descendente de uma família japonesa tradicional; Ellen, uma hacker que sofre preconceito no colégio por ser negra e pobre; e Lica, uma jovem rebelde de família rica que forma com outra personagem o primeiro casal de mulheres da novela.

Lica começa namorando um garoto da escola e depois de dar um selinho em Samantha, uma colega das protagonistas, em uma festa, as duas começam um relacionamento instável inicialmente e que vai, com o passar dos episódios, se fortalecendo. Na trama da novela há uma disputa entre duas escolas, uma particular e uma pública. Em um episódio próximo ao fim da temporada, uma das representantes da escola particular espalha um vídeo mentiroso sobre a outra instituição, com medo de que as matrículas em sua escola diminuam no ano seguinte, perdendo espaço devido à qualidade do ensino oferecido pela escola pública. Um dos fatos "escandalosos" do tal vídeo é um beijo de Samantha e Lica.

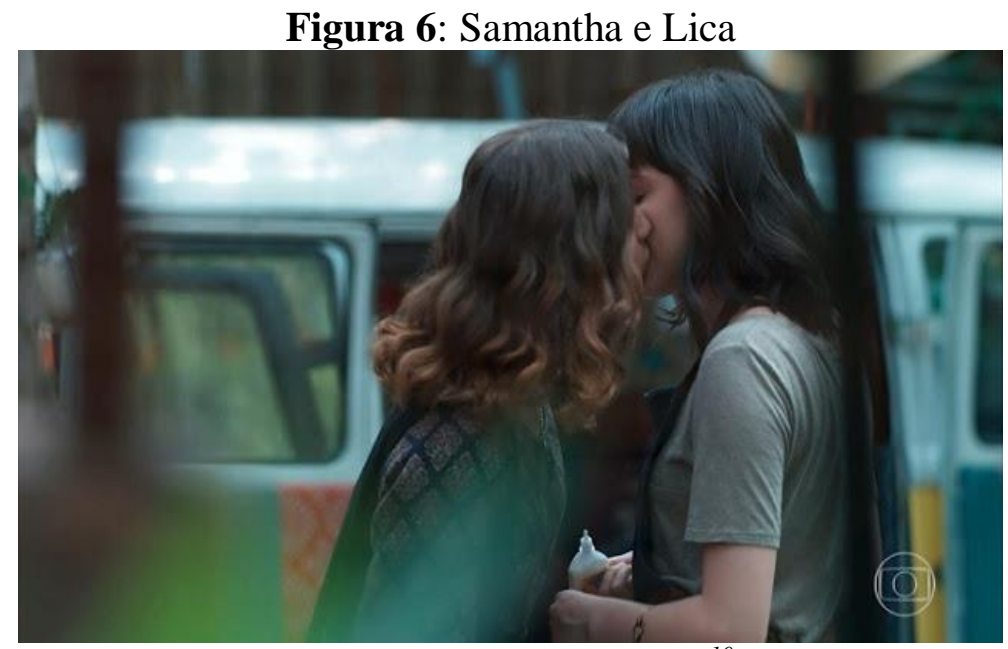

Fonte: Preta, Nerd e BurningHell ${ }^{10}$

A referida campanha de difamação alega que a escola estimula a "pouca vergonha",

\footnotetext{
${ }^{10} \mathrm{http} / / /$ www.pretaenerd.com.br/2018/03/malhacao-viva-diferenca.html
}

Rev. Eletrônica Mestr. Educ. Ambient. Rio Grande, Dossiê temático "Imagens: resistências e criações cotidianas", p.230-252, jun. 2020. E-ISSN 1517-1256 
a imoralidade e incentiva a homossexualidade. Na trama ficcional, a alegação se aproxima daquela feita pelo atual Ministro da Educação na busca por deslegitimar a qualidade das universidades públicas brasileiras, com um suposto "argumento" de que elas promoveriam a balbúrdia (EL PAÍS, 2019).

A temporada teve sucesso de audiência e os vídeos feitos por fãs que apresentavam os momentos de Lica e Samantha juntas se tornaram consideravelmente numerosos com milhares de visualizações. Devido à popularidade, em 2019 foi anunciado que a temporada receberia um Spin Off, ou seja, uma nova produção derivada dela, feita exclusivamente para streaming na plataforma Globoplay, na qual se focalizará a vida das personagens na fase adulta. Vale notar que essa temporada da novela, com a dinâmica e relação das jovens lésbicas foi, depois de 12 anos, a primeira temporada da novela a ser licenciada para exibição em outros países (Rangel QUERINO, 2018).

Diferentemente das narrativas citadas anteriormente, Anne Withan E não traz adolescentes abertamente lésbicas ou bissexuais, nem lida diretamente com a descoberta da lesbianidade/bissexualidade de uma jovem mulher. A série é uma adaptação do livro Anne de Green Gables, da escritora canadense Lucy Maud Montgomery (2018), publicado originalmente em 1908.A produção para TV é uma realização do canal canadense CBC e a série é distribuída também pela Netflix, o que configura ainda outra possibilidade de dinâmica diferente daquelas vistas até aqui nas demais produções analisadas, com alianças entre os canais de televisão e os sites de streaming. Cumpre destacar que tais alianças de produção e exibição podem traçar rumos de roteiros, de continuidade de cancelamento das séries, de modo a inaugurar interações que não existiam desta maneira antes dos acessos a essas produções se darem pela internet, assim como não existiam, em momento préinternet, icomo conhecemos, a intensa interação entre fãs, movimentos sociais e as suas influências nos roteiros, na produção e na exibição.

A narrativa deAnne Withan E trata das aventuras de uma garota, Anne Shirley, que é adotada pelos irmãos Marilla e MathewCuthbert, passando então a residir na região rural fictícia de Avonlea na Ilha do Príncipe Eduardo no Canadá.

Figura 7: "Eu serei a heroína da minha própria história", forte imagem e mensagem deAnne Withan E 


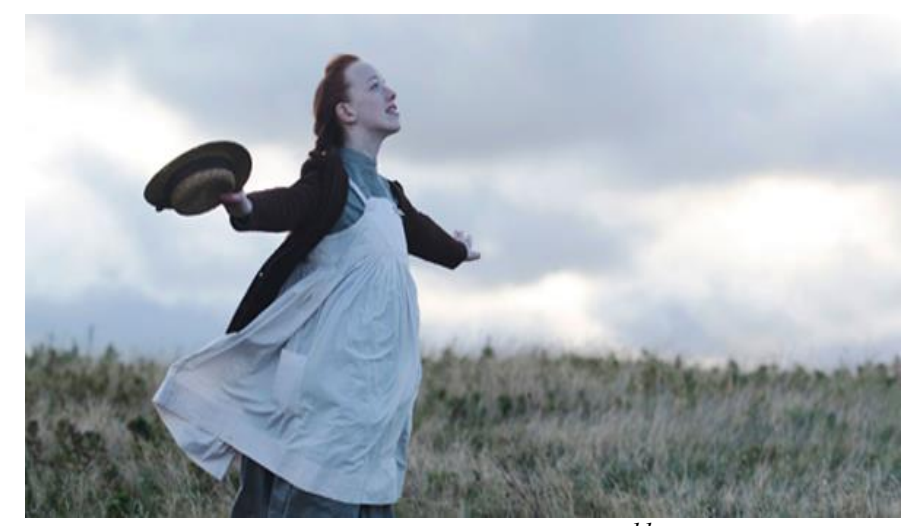

Fonte: Chimichangas ${ }^{11}$

Na segunda temporada é introduzida uma nova personagem no núcleo juvenil da série, um garoto chamado Cole, que sofre com provocações e agressões de colegas por apresentar trejeitos e gostos considerados não masculinos. No sétimo episódio da temporada, Anne, sua amiga Diana e Cole tramam um plano para que seus responsáveis os deixem ir a uma festa na casa da tia-avó de Diana, Josephine Barry, uma mulher idosa e lésbica. Apesar de já ter aparecido anteriormente na série e ter deixado indícios de sua lesbianidade, é somente nesse episódio que o tema aparece mais evidente na narrativa.

Cada uma das jovens reage de forma diferente a essa revelação. Enquanto Anne fica maravilhada com a profundidade do amor entre Josephine e sua falecida esposa Gertrude, Diana se questiona se a tia-avó não estaria errada por ter escondido aquele "estilo de vida" e se aquilo não seria "antinatural", como dizem concepções preconceituosas. Já Cole encontra em Josephine uma perspectiva de que, no futuro, ele possa viver longe de agressões, semelhante ao que ocorre no episódio citado, no presente texto, de EverythingSucks!(2018). Cole compartilha suas aflições com Josephine e ela responde que ele tem uma vida feliz pela frente, com dificuldades e pedras pelo caminho, mas que encontrará aqueles em quem confiar. Essa interação não concorre para retratar a lesbianidade como equivalente feminino da homossexualidade masculina, mas pode ser indício da possibilidade de uma solidariedade entre as pessoas que compartilham essas identidades e compõem tais grupos populacionais.

Anne de Green Gables é considerado um livro clássico infanto-juvenil em vários países de língua inglesa. As aventuras de Anne já foram adaptadas em obras audiovisuais diversas vezes, entre filmes e outras séries. A atual versão deAnne Withan E (2017)teve sua adaptação comandada por uma mulher, Moira Walley-Beckett, é frequentemente apontada como detentora de uma perspectiva muito mais feminista que as anteriores. Ter mulheres

\footnotetext{
${ }^{11}$ https://www.chimichangas.com.br/series/o-debate-do-feminismo-em-anne-with-an-e-o-que-aprendemos-com-anneshirley/1

Rev. Eletrônica Mestr. Educ. Ambient. Rio Grande, Dossiê temático "Imagens: resistências e criações cotidianas", p.230-252, jun. 2020. E-ISSN 1517-1256
} 
assumindo a produção de séries feitas para o grande público é um tema que importa. Construir narrativas audiovisuais é, como aponta Michelle Citron (1990, p.62), um risco, mas que é necessário ser assumido para que pontos de vistas desenvolvidos por mulheres possam tomar vida na frente do grande público. Este, afinal, é também composto, pelo menos em sua metade,por mulheres. Esse direcionamento da abordagem da série tem sido apontado com entusiasmo por parte dos fãs e da crítica, que salientam a forma como a série pode promover modelos femininos positivos para as novas gerações. Por outro lado, desde a primeira temporada, é possível encontrar na internet numerosos artigos de opinião, comentários nas postagens em redes sociais da Netflix e em fóruns. Tais comentários alegam que a série seria muito pesada, pois introduziria questões polêmicas e com enfática visão feminista, a qual não combinaria com a concepção original proposta em Anne Withan E.Como mencionado, a obra oriunda dessa produção é considerada clássica, ao que concordamos. Acrescentamos ainda o que Italo Calvino afirma sobre livros e transpomos para produções audiovisuais: "Um clássico é um livro que nunca terminou de dizer aquilo que tinha para dizer" (CALVINO, 1998, p.11). Nesse sentido, o livro de Green Gables traz um conjunto de dizeres a serem explorados e reside aí seu caráter clássico, pois são aqueles livros dos quais se diz "estou relendo..., e nunca "estou lendo", como também aponta Calvino (1998, p.9) e pode ser aplicado nessa releitura audiovisual da obra escrita.

Apesar dessas ricas releituras e novos encaminhamentos das séries, nas mais variadas mídias e suportes em que se inscrevem, há um longo caminho a percorrer na direção de termos um final feliz à frente, em um futuro que parecedistante.

\section{Lésbicas e bissexuais em silêncios que gritam, como considerações finais}

"as ferramentas do senhor nunca vão derrubar a casa-grande"

"sermos mulheres juntas não era o suficiente. éramos diferentes.

sermos garotas homo juntas não era suficiente. éramos diferentes. sermos negras juntas não era suficiente. éramos diferentes. sermos mulheres negras juntas não era suficiente. éramos diferentes. sermos sapatas negras juntas não era suficiente. éramos diferentes... levou um tempo para percebermos que nosso lugar era não a segurança de uma diferença em particular, mas a própria casa da diferença."

No texto "As ferramentas do senhor nunca vão derrubar a casa-grande", Audre Lorde (1979) questiona sua participação na única mesa-redonda da conferência do Instituto de Humanidades da Universidade de Nova York, na qual a discussão era sobre questões 
das mulheres negras e lésbicas. Recuperamos aqui esse questionamento de Lorde, pois, por mais que as produções seriadas analisadas tragam avanços em termos de representação para algumas mulheres lésbicas e bissexuais, essas mesmas produções carregam a ausência de lésbicas e bissexuais negras adolescentes. Seria um modo de repetir o problema da pouca ou nenhuma representatividade de mulheres negras, como em outras produções audiovisuais. Encerramos, assim, o presente texto com um questionamento a partir da obra de Audre Lorde e das séries analisadas, além de informações relacionadas a esse diálogo que tecemos.

Seria a busca por representatividade nas produções seriadas uma maneira de adotar as ferramentas do senhor, sem nos darmos conta que a inclusão que encontramos não corresponde à igualdade de direitos e reparação histórica, por todo o silenciamento de um "nós" muito mais diverso do que pode retratar o atual universo das produções existentes?

Há dados que permitem pensar em respostas para esse questionamento. Segundo a Agência Nacional de Cinema(ANCINE) no ano de 2016, dos 142 longa metragens lançados, 75,4\% foram dirigidos por homens; e nenhum dos 24,6\% restantes foram dirigidos por mulheres negras. Apenas três desses filmes tiveram um negro ou pardo na direção. Tais dados expressam a ausência de produção de mulheres negras no mercado nacional (Yasmine EVARISTO, 2018).

A cineasta Viviane Ferreira - também advogada especializada em direitos autorais, direito cultural e direito público - nos relembra que o direito de se sonhar como grupo, a partir das construções na ficção, no cinema, é uma ferramenta política. A obra de Ferreira nos mostra que o cinema negro - assim como produções seriadas para jovens mulheres lésbicas e bissexuais negras - tem a potencialidade de transportar a subjetividade a partir da linguagem audiovisual, o que é um direito das adolescentes negras lésbicas e bissexuais, como é direito de qualquer outro grupo social (ITAÚ CULTURAL, 2017). Na direção de implementar esse direito no cinema negro, Viviane Ferreira, em 2017, buscou financiamento coletivo para a série Ufa!Falei, que previa ser estruturada em 7 episódios, de 26 minutos de duração. Os temas abordados seriam desde os conflitos no momento de assumir a orientação sexual para a família, pedir outra mulher em namoro ou casamento, até a decisão de contar a um ex-namorado que se apaixonou por uma mulher, passando por demandar o uso de preservativo na relação com uma mulher e também terminar um relacionamento entre mulheres (Pedro BORGES, 2017). De 2017 até o momento de escrita do presente texto, pouco tempo se passou, mas muitos tensionamentos de retrocesso foram e estão sendo vivenciados, no Brasil, sobretudo por mulheres negras, lésbicas e bissexuais, 
de variadas idades, com especificidades geracionais e também de identidade de gênero, ao lado da orientação sexual, que focalizamos nessa escrita. Mesmo que a série não tenha sido lançada ainda, pensar e divulgar sua ideia é algo que anima e mostra que, apesar das mudanças percebidas a partir da pesquisa aqui noticiada, é preciso discutir como alargar e solidificar a presença de representações de populações vistas como minorias sociais, entre elas as mulheres negras lésbicas e bissexuais, no sentido de garantir o direito à comunicação.

As transformações já observadas estão relacionadas às possibilidades criadas com novos recursos tecnológicos e (também) pelas reivindicações e mobilizações de tais minorias. Para que essas mudanças continuem, é necessário debater como esse acesso pode se tornar ainda mais amplo, efetivando a cidadania em suas dimensões política, econômica, social e cultural, como aponta Cicilia Peruzzo (2005). A presença de lésbicas e bissexuais - jovens, idosas, de diferentes etnias -em séries para adolescentes fortalece a identidade dessas jovens. As produções já existentes e as planejadas, como Ufa! Falei!, com a presença de lésbicas e bissexuais tendo voz, proposta por Viviane Ferreira, colaboram para quebrar o silêncio ainda imposto a grupos minoritários. Tais mudanças, com representação e visibilidade na mídia, podem contribuir com o exercício do direito à comunicação e, assim, com a identidade e cidadania de lésbicas e mulheres bissexuais, de todas gerações, desde que consigam queas ferramentas percebidas como do senhor sejam apropriadas por todas as pessoas.Ainda que tentem nos atrasar, estamos seguras de que conseguiremos!

Figura 8: O direito de se sonhar como grupo no cinema é uma ferramenta política, como lembra a cineasta Viviane Ferreira.

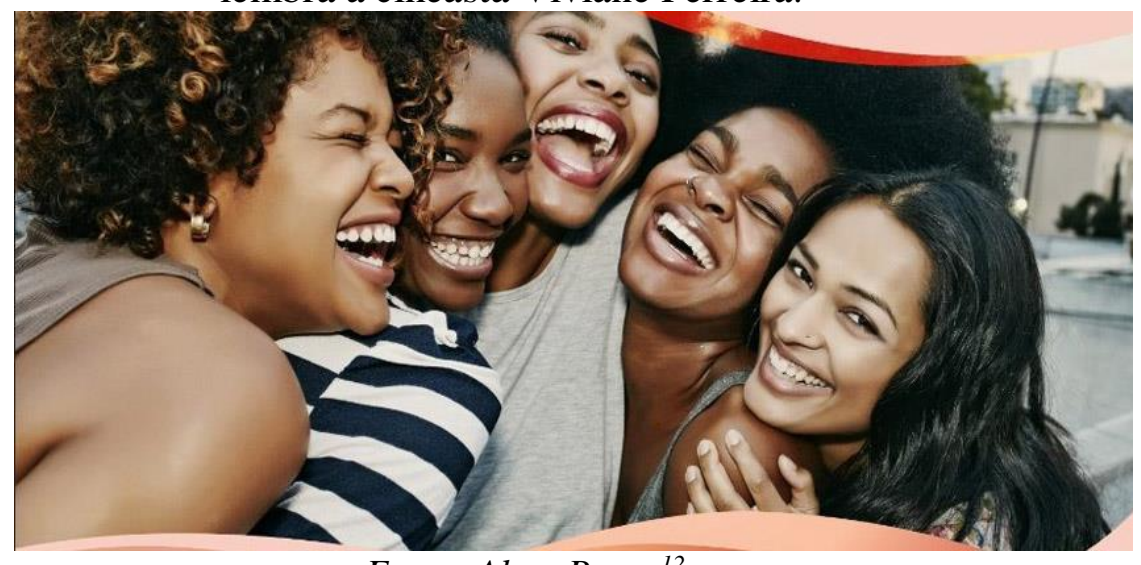

Fonte: Alma Preta. ${ }^{12}$

\footnotetext{
${ }^{12}$ Para mais informações sobre a agência de jornalismo Alma Preta, especializada em temática racial no Brasil, acessar: https://almapreta.com.
}

Rev. Eletrônica Mestr. Educ. Ambient. Rio Grande, Dossiê temático "Imagens: resistências e criações cotidianas", p.230-252, jun. 2020. E-ISSN 1517-1256 


\section{Referências}

AMOS, Tori. Silent all theses years. In: AMOS, Tori. Little Earthquakes.Los Angeles: Atlantic Records, 1992. Disponível em:

https://open.spotify.com/album/5bxqwBKvCyB67zOEVCrFZE.Acesso em: 04 nov. 2019.

ANNE with an E. Criação de Moira Walley-beckett. Intérpretes: AmybethMcnulty, Geraldine James, R.h. Thomson. Canadá: CBC e Netflix, 2017. Son., color. Legendado. Disponível em: https://www.netflix.com/title/80136311. Acessoem: 11 nov. 2019.

ASSIS, Ryan Brandão Barbosa Reinh de; AUAD, Daniela; LAHNI, Cláudia Regina. Educação e Cidadania na TV: um estudo sobre Glee. In: $1^{\circ}$ Seminário Internacional Diferenças e Educação, 2013, Juiz de Fora. Anais [...],v. 1, p. 553-565.Juiz de Fora: UFJF - Neped, 2013.

BEIRNE, Rebecca. Teen Lesbian Desires and Identities in International Cinema: 19312007. Journal of Lesbian Studies, Londres, v. 16, n. 3, p.258-272, jul. 2012.

BERTRAN, Agustin. Globo quer investir R \$ 1 bilhão no GloboPlay e em novas tecnologias em 2020. Nextv Brasil, 22 nov. 2019. Disponível em: https://nextvbrasil.com/globo-quer-investir-r-1-bilhao-no-globoplay-e-em-novastecnologias-em-2020/. Acesso em: 27 abril 2020.

BONFIM, Mariana. StrangerThings é das MULHERES. Minas Nerds, 10 jul. 2019. Disponível em: http://minasnerds.com.br/2019/07/10/stranger-things-e-das-mulheres/. Acesso em: 27 abril 2020.

BORGES, Pedro. Série busca mulheres lésbicas e bissexuais que queiram dividir suas histórias. Alma Preta, 10 abr. 2017. Disponível em:

https://almapreta.com/editorias/realidade/serie-busca-mulheres-lesbicas-e-bissexuais-quequeiram-dividir-suas-historias. Acesso em: 27 abril 2020.

CALVINO, Italo. Por que ler os Clássicos. São Paulo: Companhia das Letras, 1993.

CASTELLANO, Mayka; MEIMARIDIS, Melina. Produção Televisiva e Instrumentalização da Nostalgia: O caso Netflix. RevistaGEMInIS, v. 8, n. 1, p. 60-86, 19 jul. 2017.

CERDEIRA, Camila. Malhação Viva A Diferença. Preta, Nerd e BurningHell, 07 mar. 2018. Disponível em: www.pretaenerd.com.br/2018/03/malhacao-viva-diferenca.html. Acesso em: 27 abril 2020.

CITRON, Michelle. Women's Film Production: Going Mainstream. In: PRIBRAM, E. Deidre. Female Spectators: Looking at Films and Television. Londres: Verso, 1990. p. 45-63.

COUTINHO, Lídia Miranda. A telenovela Malhação e seus modos de endereçamento. Inovcom Sul, 2008.Anais [...], 2008. 
DEMARCHI, Helena. O debate do feminismo em Anne withan E: O que aprendemos com Anne Shirley? Chimichangas, 09 mar. 2020. Disponível em:

https://www.chimichangas.com.br/series/o-debate-do-feminismo-em-anne-with-an-e-oque-aprendemos-com-anne-shirley/. Acesso em: 27 abril 2020.

EL PAÍS. Protestos contra cortes na educação: "O que o presidente diz é uma ofensa a nós que viemos às ruas”. El País Brasil, 16 maio 2019. Disponível em:

https://brasil.elpais.com/brasil/2019/05/15/politica/1557925930_773928.html. Acesso em: 27 abril 2020.

EUPHORIA. Criação de Sam Levinson. Intérpretes: Zendaya, Maude Apatow, Angus Cloud. EUA: Netflix, 2019. Son., color.

EVARISTO, Yasmine. O Dia de Jerusa: a urgência da representação e da representatividade. Plano Aberto, 23 ago. 2018. Disponível em:

https://www.planoaberto.com.br/o-dia-de-jerusa. Acesso em: 27 abril 2020.

EVERYTHING Sucks!. Criação de Ben York Jones e Michael Mohan. Intérpretes: JahiDi'allo Winston, Peyton Kennedy, Patch Darragh. EUA: Netflix, 2018. Son., color. Disponível em: www.netflix.com/watch/80117713. Acesso em: 11 nov. 2019.

GÓMEZ, Guillermo Orozco. Educomunicação: Recepção midiática, aprendizagem e cidadania. São Paulo: Paulinas, 2014. 168 p.

HOOKS, bell. De quem é essa buceta?: um comentário feminista. In: ADELMAN, Miriam et al.(Org.). Mulheres, homens, olhares e cenas. Curitiba: Editora UFPR, 2011. p. 197205.

ITAÚ CULTURAL. Viviane Ferreira - Diálogos Ausentes (2016). YouTube, 3 abr. 2017. Disponível em: www.youtube.com/watch?v=MOJ3nJPSW9A. Acesso em: 27 abril 2020.

KINOCHECK INTERNACIONAL. Everything Sucks! Trailer (2018) Netflix. YouTube, 6 fev. 2018. Disponível em: www. youtube.com/watch?v=-mMr16Xt2Fc. Acesso em: 27 abril 2020.

LAHNI, Cláudia Regina; AUAD, Daniela. Feminismos e direito à comunicação: lésbicas, bissexuais e transexuais em série. Laplage em Revista, Sorocaba, v. 4, n. 1, p.93-108, jan./abr. 2018. Disponível em:

www.laplageemrevista.ufscar.br/index.php/lpg/article/view/439. Acesso em: 07 out. 2019.

LAHNI, Cláudia Regina; AUAD, Daniela. As lésbicas têm espaço no jornalismo?

Presenças e ausências lesbianas na comunicação. In: SOARES, Mayana Rocha;

BRANDÃO, Simone; LORDE, Audre. audre lorde. confabulando, s/d. Disponível em: http://kk2011.confabulando.org/index.php/Main/AudreLorde. Acesso em: 27 abril 2020.

MAGALHÃES, Letícia. Aprendendo com a Vovó (2015). Cine Suffragette, 22 set. 2027. Disponível em: https://medium.com/cinesuffragette/aprendendo-com-a-vov\%C3\%B32015-b43b4ff47507. Acesso em: 27 abril 2020. 
MALHAÇÃO: Viva a Diferença. Direção de Paulo Silvestrini. Intérpretes: Gabriela Medvedovski, Daphne Bozaski, Ana Hikari,Heslaine Vieira, Manoela Aliperti. São Paulo: Globo, 2017-2018. Son., color.

MARTIN-BARBERO, Jesús. Dos meios às mediações: Comunicação, cultura e hegemonia. 2.ed. Rio de Janeiro: Editora da UFRJ, 2003.

MATA, Maria Cristina. Os silenciados e a comunicação na América Latina. Entrevista Especial com Maria Cristina Mata. EcoDebate, 18 fev. 2010.

MEDEIROS, Lucas. Malhação ganha seu primeiro casal lésbico; relembre outros casais nas novelas. O TV Foco, 19 dez. 2017. Disponível em: www.otvfoco.com.br/malhacaoganha-seu-primeiro-casal-lesbico-relembre-outros-casais-nas-novelas/. Acesso em: 27 abril 2020.

MIRANDA, Wagner Rodrigues. Produzir e ver o audiovisual na cibercultura:novos hábitos na contemporaneidade. Belo Horizonte, 2017. 140 f. Dissertação (Mestrado em Artes) - Escola de Belas Artes, Universidade Federal de Minas Gerais. Disponível em: https://repositorio.ufmg.br/handle/1843/BUBD-APEPYS. Acesso em: 15 set. 2019.

MONTGOMERY, Lucy Maud. Anne de Green Gables. Martins: Pedra Azul, 2018. 236 p.

NETFLIX. Comunicados à imprensa. Netflix Media Center. Netflix, s/d. Disponível em: https://media.netflix.com/pt_br/press-releases. Acesso em: 27 abril 2020.

NOGUEIRA, Nádia. Invenções de si em histórias de amor: Lota Macedo Soares e Elizabeth Bishop. Campinas, 2005. Tese (Doutorado)- Universidade de Campinas.

NOGUEIRA, Nádia. Invenções de si em histórias de amor: Lota Macedo Soares e Elizabeth Bishop. Rio de Janeiro:Apicuri, 2008.

ONE Day at a Time. Criação de Gloria CalderonKellett e Mike Royce. Intérpretes: Justina Machado, Todd Grinnell, Isabella Gomez. EUA: Netflix, 2017. Son., color.Disponível em: www.netflix.com/watch/801 18600?trackId=200257859. Acesso em: 11 nov. 2019.

PERUZZO, Cicilia M. K. Internet e Democracia comunicacional: Entre os Entraves, Utopias e o Direito à comunicação. In: MELO, José Marques de; SATHLER, Luciano (Org.). Direitos à Comunicação na Sociedade da Informação. São Bernardo do Campo: Umesp, 2005. p. 267-288.

PETITE, Luana. Entre versos e samambaia: O encontro de Elizabeth Bishop e Lota de Macedo Soares. Valkirias, 30 jan. 2018. Disponível em: http://valkirias.com.br/entreversos-e-samambaia-elizabeth-bishop-lota-soares/. Acesso em: 27 abril 2020.

PROCURA-SE Amy. Direção de Kevin Smith. EUA, 1997. Son., color. Legendado.

QUERINO, Rangel. Com casal lésbico, sucesso de Malhação faz Globo vender novela para o exterior. Observatório G, 19 jan. 2018. Disponível em: 
https://observatoriog.bol.uol.com.br/noticias/2018/01/com-casal-lesbico-sucesso-demalhacao-faz-globo-vender-novela-para-o-exterior. Acesso em: 27 abril 2020.

RICH, Adrienne.Heterossexualidade Compulsória e Existência Lésbica e Outros Ensaios. Rio de Janeiro: A Bolha Editora, 2019. 164 p.

RIO, Mariana. EverythingSucks!: Os anos 90 e os dilemas da adolescência. Delirium Nerd, 11 abr. 2018. Disponível em: https://deliriumnerd.com/2018/04/11/everythingsucks-anos-90/. Acesso em: 27 abril 2020.

SILVA, Carlos Eduardo Lins da. As brechas da indústria cultural brasileira. In: FESTA, Regina; e SILVA, Carlos Eduardo Lins da (Org.). Comunicação popular e alternativa no Brasil. São Paulo: Paulinas, 1986.

STRANGER Things. Criação de Matt Duffer e Ross Duffer. EUA: Netflix, 2016. Son, color.

SOMMELIER DE OPINIÃO. Onedayat a time - depressão, temas LGBTQ, feminismo e a necessidade da esperança. Sommelier de opinião, 28 jan. 2018. Disponível em: https://medium.com/@ sommelierdeopiniao/one-day-at-a-time-depress\%C3\%A3o-temaslgbtq-feminismo-e-a-necessidade-da-esperan\%C3\%A7a-2f46c3a2ac40. Acesso em: 27 abril 2020.

YOUTUBE. YouTube para a imprensa. YouTube, s/d. Disponível em: www.youtube.com/intl/pt-BR/about/press/. Acesso em: 27 abril 2020.

Submetido em: 30-04-2020.

Publicado em: 01-07-2020. 